\title{
Leading While Female: A Personal Journey
}

\author{
Linda Katehi
}

\begin{abstract}
Growth in the administrative function of universities along with the fragility of academic culture creates challenges for academic leaders invested in change. In my own case, these challenges were compounded by my gender: my status as an immigrant woman in a leadership role. In this chapter I outline the basic requirements of a democratic culture - allowing individuals to preserve their identity while positively contributing to the community in which they're embedded-and question the gender stereotypes that see men but not women as "naturally" suited to leadership. This prejudice can translate into implicit or even explicit bias and discrimination when women attempt to fill roles that historically have been reserved for men, and thereby violate gender expectations. As a consequence, women leaders may be marginalized and their authority resisted or unrecognized. This chapter is a personal journey detailing my own experiences of "leading while female."
\end{abstract}

Keywords Leadership - Cultural change $\cdot$ Institutional transformation $\cdot$ Academic culture

\section{Culture in the Context of Institutional Transformation}

According to the European Institute for Gender Equality (European, 2019), institutional transformation implies profound change; it encompasses changes in rules, policies, and practices whose outcomes may, in turn, trigger fundamental changes in the basic values and beliefs dominant in the institution's culture. As we try to understand institutional transformation and the role of an institution's leadership, it is important to consider the meanings and impacts of culture. From an evolutionary perspective, Plotkin $(1994,2003,2007,2011)$ argues that culture is essentially a kind of collective identity; as individuals create and share with others their stories, experiences, ideas, and beliefs, diverse ideologies eventually congregate, enabling a consciousness that represents a collective "intentionality" (Plotkin, 2003).

\section{Katehi $(\varangle)$}

Department of Electrical and Computer Engineering, University of California, Davis, Davis, CA 95616, USA

e-mail: katehi@ucdavis.edu 
The transition from individual intensions to collective ones, while slow and chaotic in nature and form, enables social evolutionary change. The Athenians called this process "democracy" (Thorley, 1996). For a democratic culture to thrive and provide the foundation for positive change, three elements are necessary: (1) freedom to express ideas and opinions, (2) freedom to safely and openly contest them, and (3) ability to respect the opinion of the majority without having to surrender one's personal beliefs. A democratic culture is the structure that seems most capable of moderating the impact of cultural conformity on personal freedoms; it encourages individuals to preserve their identity while acting as positive contributors to their community. By contrast, cultures that suppress speech and use force and intimidation to impose on the wider community values and beliefs that benefit only a small group result in oppressive or oligarchic regimes i.e., colonialism, fascism, totalitarianism, and some forms of communism. Because the majority is forced to follow expectations that largely benefit a minority, the cultures of such regimes may become socially unstable and require continuous application of force to survive.

An extensive literature on culture has been published spanning a broad spectrum of approaches, from anthropological (Benedict, 1938; Boaz, 1915; Mead, 1970) and linguistic (Mandelbaum, 1985) to biological (Darwin, 1892) and socioeconomic (Marx, 1911). This early work laid the foundation for much contemporary scholarship (see Moon \& Kern, 2002; Baldwin et al., 2006). For the purposes of this chapter, I will discuss what we call "academic culture," and then critique this culture for its view of gender within the professorial ranks.

The following definition of culture embraces most trends (Baldwin, 2017) and uniquely applies to academic institutions:

Culture is the way of life of a group of academics including faculty, student, and staff who believe in the shared principles of academic freedom and freedom of speech, and aspire to excel in teaching, research and service. This culture continually evolves impacted by the clash between individual beliefs, perspectives and interests, power relationships and institutional expectations for academic excellence, merit, equal opportunity and social justice.

In a large institution such as a university, what the academic community intends may be at odds with what individual members want. This discrepancy, when systemic, leads to conflicts of consciousness or commitment and may eventually give rise to outright dissent. Instead of excluding or marginalizing individuals or subgroups with opposing views, progressive cultures typically allow personal beliefs and values to be freely expressed, debated, and even practiced, as long as these practices do not harm the community and oppress others. This process helps communities achieve concerted and sustained agreement. It represents a fragile balance of conflicting perspectives that, when sustained, can bring progressive change and cultural transformation. 


\section{Cultural Stereotyping, Prejudice, and Bias}

Research on intergroup psychology suggests that many social attitudes, including stereotypes, are implicit. At the same time, there is little agreement on how implicit stereotypes and expressed prejudice are related. Whether the relation between the two is viewed as weak (Amodio, 2009, 2011; Correll, 2007; Forbes, 2010; Glaser, 1999; Judd, 2004; Valian, 1998, 2009) or strong (Gawronski, 2006; Gawronski \& Bodenhausen, 2011; Greenwald, 2002), it is widely recognized that efforts to address implicit bias should attempt to achieve the following two objectives: (1) retrain the brain to form positive stereotypes (as, for example, "women can in fact excel in math and physics"), and (2) negate prejudice by educating the community on issues of implicit bias (Madva, 2016; Mazda \& Brownstein, 2016).

Every culture enables forms of prejudice that may be more or less overt depending on how much they deviate from accepted social norms. For example, stereotyping homeless people as mentally-ill substance abusers results in prejudice that is largely tolerated in the United States the same way that stereotyping and prejudice against gypsies is largely tolerated in Europe. Prejudice against atheists is openly tolerated and even promoted in some parts of the world in the same way that anti-Semitism was tolerated in Europe until the end of World War II. When forms of prejudice are uncontested, it gives people permission to enact biases either explicitly or implicitly. In Western post-industrial societies today, prejudices stemming from racism, anti-Semitism, Islamophobia, homophobia, sexism, and gender discrimination are generally discouraged as they are considered incompatible with prevailing social norms and values.

Prejudice is not always motivated by hate; it may be motivated by a desire to preserve a status quo and/or affirm tradition. Consider that, until fairly recently in U.S. history, many women, with the notable exception of black women, were expected to be wives and homemakers rather than breadwinners. When women violate this expectation, they may be stereotyped. When I was a faculty member at the University of Michigan in the late 1980s, some politically-motivated groups on campus claimed that daycare centers slowed the emotional growth of preschoolers. These groups began characterizing working mothers as "competent professionals who occupied the role of a mother part of their time." Mothering "part-time" was a negative characterization that quickly found its way into grade-school classroom gossip and gave rise to prejudice against girls with working mothers. Girls subsequently formed their own in-groups whose mothers stayed at home and actively participated in school functions, and out-groups whose mothers held down jobs and were unable to participate in school activities that interfered with their work responsibilities.

With the massive entry of women into the workforce in recent decades, stereotyping working moms has generally given way to stereotyping women working in specific professions. For example, studies show that people associate men's names with high-income, high-status occupational roles (faculty member, manager, director, scientist, physician, mathematician, engineer) but women's names with lower-income, lower-status roles (assistant, teacher, nurse, caregiver). This can lead 
to both implicit and explicit prejudice toward women who happen to fill "traditional" men's jobs (Rudman \& Kilianski, 2000).

Researchers find that prejudice against female authority is often a result of stereotyping men (and white men especially) as "rightfully" exercising power and influence, while simultaneously highlighting women's professional inadequacies (Mazda $\&$ Brownstein, 2016). This holds true even in professional occupations where women have made significant inroads. Women may be viewed as legitimate careerists and able to teach math or engineering in a college or research university, fly an A380 airliner, or perform brain surgery. However, when women violate expectations that apply to white men only, i.e., be powerful leaders - chair of a department, dean of a college, chancellor or president of a research university, head pilot of a 747, CEO of a hospital, or president of a National Academy - their authority in the department, college, campus, plane, hospital, and Academy may not be welcome or even recognized.

The implicit stereotyping of subordinate groups - in this case, women leadersand expressions of prejudice toward them, when shared by members of dominant groups within an organization or an academic institution, undermines inclusivity and creates social instability. Research on implicit bias demonstrates that when individuals feel supported in what they consider acceptable, they feel empowered to act in discriminatory ways even in the absence of an organizational prejudice. Stereotypes held about leadership abilities, for example, might cause a selection committee to discriminate against women when looking to fill a leadership position, even though the employer or larger organization openly is against gender discrimination. Experimental research by Flannigan et al. (2013) found that men and women in counterstereotypical roles (such as male nurses or female pilots) were considered by research subjects to be "implicitly bad," leading some subjects-disproportionately men-to dislike or distrust them.

When implicit bias conflicts with the organizational goal of nondiscrimination, individuals, both men and women, may question (mostly privately but sometimes openly) the fit of women and underrepresented minorities in the "hard-working" roles traditionally and historically occupied by white men without disliking those they consider unfit for the role. This is consistent with the findings of Rudman and Ashmore (2007) as well as Ebert (2009) that men may like women, but do not associate them with leadership necessarily. Implicit bias is more likely to become explicit if the target is a member of marginalized out-group Jacobs and Campbell, D. T. (1961). For example, in my experience, international or immigrant women filling leadership roles are frequently viewed with suspicion and their rights, intentions, and abilities are openly questioned.

\section{Academic Culture}

There are three main constituencies that make up the university—students, faculty, and staff_-each with its own priorities and areas of influence. Students want access to 
high-quality education and good preparation for a successful professional life. Their choices about how to expand university resources would positively impact students exclusively, and faculty to a lesser degree. By contrast, faculty are mostly attached to their professional communities, believing that their success in that space leads to their professional and academic advancement. As a result, they want to demonstrate their worth to their national and international colleagues, so they often favor quality in academic programs and research. In contrast to the interests of students and faculty, staff usually see the university as an employer on whom they depend for a steady and satisfying job, appropriate benefits, and wages that match their qualifications. They expect a predictable working environment, prefer a decent salary program, and wish for continuous professional development. Of the three, the staff are the most stable population and as a result see themselves as the most loyal to the institution. The relative size and pace of growth among the three groups has changed over time. The vast post-Cold War expansion of academic degree programs, the proliferation of student services and sports, the increase in state and federal regulations, and the rise of academic medical hospitals throughout the United States have led to substantial growth in the numbers of students attending college and in relevant auxiliary services. As a result, the rate of increase of staff, both academic and administrative, and of students has substantially outpaced that of faculty.

Divergent interests and asymmetrical growth among the three constituencies contributes to the dynamic fragility of academic culture. The erosion of state support for higher education during the past 30 years and the imposed restructuring of university funding mechanisms involving new economic models has exacerbated this fragility, as do a host of other factors-including the transitional nature of the student community, the stratification of the academic professions, the uneven distribution of academic and administrative power, and a growing mistrust of administrative leadership. Efforts to sustain any type of progressive culture under such conditions has become increasingly difficult, making it almost impossible to define "progress" holistically and create a "normative platform" for change.

Fragility in culture is like a double-edged sword. It generates conflicts of principles or values which may lead to either positive transformation or distractive fragmentation of the community in question. Which side of the sword defines the community - in this case, the university - depends on whether it is driven by hope or hostility and whether it can sustain its institutional vigor while embracing dissent and withstanding conflict. Such fragility places a burden on leaders to provide an environment that both values inquiry and affords opportunities for constructive debate. It requires academic leadership at all levels to place the well-being and vibrancy of the university above individual benefit and influence. The lack of such leadership overwhelms progressive change, reinforces suspicions, and strengthens stereotypes.

Why is the nature of academic culture and leadership so important in identifying which actions have the potential to eradicate gender inequality and gender discrimination in academia? Based on 40 years of personal experience in four universities as a faculty member and administrator, I believe that sustained, positive change cannot easily be achieved in an environment as fragile in culture and weakened in leadership as that of the American public university today. American academic culture reminds 
me of the John Lennon Wall in Prague. Once a regular wall, it was first decorated in the 1980s by an artist who painted an image of the famous singer and cultural icon, John Lennon, after Lennon's assassination in New York. Since then, the wall has been undergoing continuous change, sometimes carrying coordinated messages while other times highlighting the broad diversity of the local people's cultural sensitivities along with their conflicting interests. Now and then the wall is painted white again, in an attempt to give it a new start, only to be filled overnight with the same cacophony of messages.

\section{Challenges of Academic Leadership}

Institutions of higher education are complex, multi-faceted, and evolving. The transitional nature of the student body and the mobility of its faculty and staff along with the constant inflow of new community members with their own preexisting values and beliefs constitute additional challenges in sustaining a progressive academic culture. Whether this dynamism is harnessed as a force for positive change depends on the attitudes of the academic leadership. A conformist leadership will seek a point of a cultural equilibrium between stasis and change where open dialogue and critique are viewed with suspicion, are considered disruptive, and may be quietly discouraged or, at times, actively opposed. Although change can be effectively blocked by conservative forces (e.g., those vested in and loyal to the status quo), the aspirations and values of new groups (e.g., those seeking a more progressive institution) cannot be ignored. Loyalists' inability to engage these groups in meaningful dialogue fragments the culture and forces the institution away from the very cultural equilibrium they seek to achieve.

The open nature of universities, the protections of inquiry, debate, academic freedom, and freedom of speech all make fragility unavoidable. Yet, paradoxically, it is this cultural fragility that forces institutions of higher education to become places of experimentation and learning, of innovation and eventually progress. Sustaining intellectual rigor while embracing unorthodox inquiry and learning requires leaders willing to lead by example and capable of sustaining continuous dialogue and debate while also being strong enough to rebuff external politically-motivated interventions should they arise. It requires leadership that is willing to embrace ambiguity and uncertainty as issues get tested, debated or even rejected. It also requires open, continuous communication and transparent decision-making. Without such leadership capabilities, the institution becomes bureaucratic and stagnant, unable to innovate or transform.

As chancellor at UC Davis, I navigated such leadership challenges on multiple occasions with success and other with mixed results. Consider a couple of successful examples. First, I advocated increasing the number of international students from a mere $1.5 \%$ of the total student population to $15 \%$, a number more consistent with the definition of a "global" university. Because of their higher tuition, enrolling international students would have come with a commitment to also increase the 
number of Californian students. Opposition from the local academic community and state legislators reflected concerns over equity in admissions ("will they take opportunities away from Californians?") as well as institutional culture ("will they understand our lectures?"). Yet, after many months of discussion, many initially opposing groups of students, staff and faculty embraced the idea and accepted its challenges, with students becoming the most activate advocates. Within a few years, the campus completed the construction of a new International Student Center, introduced new student and faculty exchange programs, and proposed and approved new language programs - all of which helped "internationalize" the campus in ways that will increase its stature and global reach for years to come. Another challenge came when I declared that UC Davis was preparing to become a Hispanic Serving Institution (HSI). Because the effort would require significant resources, opposition came from every university unit that already supported a different form of diversity, with the view that supporting one group meant taking support away from others. In this case, allowing time for open dialogue and debate prompted rethinking on all sides and eventually enabled pursuit of the goal.

Unfortunately, for some members of the communities surrounding the university, bringing more students to campus who did not look or sound "like us" became an issue of serious disagreement as well as an expressed grievance that followed me until the end of my career as a chancellor at UC Davis. However, I believe that both efforts have made UC Davis stronger, more equitable, more open, and more visible - to the state, the nation, and the world.

An example where my efforts failed is illustrative, too. I sought to create a new affiliated campus in Sacramento that would focus on Health, Nutrition, and Public Policy. This idea had emerged from many years of trying to project the strengths of those academic fields with the capacity to address the problems and challenges of modern society with the greatest impact on people's well-being. I envisioned the new campus as a platform for making the university more visible and impactful, locally and globally. Unfortunately, despite the many years of planning, discussion with university stakeholders, and development of outside financial and political support, there was opposition. It came from academic leaders within the University of California system, community leaders from the surrounding regions, and elected officials who were uninterested in the project unless it directly enhanced their own political interests. The opposition succeeded in persuading the office of the President to withdraw support for the project at the end of 2015.

\section{The Transformative Role of NSF ADVANCE}

When I joined the University of Michigan as an assistant professor in 1984, I was one of three female faculty members in a department of 80 faculty, and one of a dozen or so in the College of Engineering. By the time I left the university in 2002 (to become the first female Dean of Engineering at Purdue), the number of women faculty had not changed substantially, while the college overall had suffered from serious attrition of 
its women faculty. One department had even systematically refused to hire women, and dared to express pride at being all-male.

This situation was not unique to the University of Michigan but reflected the reality of science, technology, engineering, and math (STEM) at that time. By the 1990s, the American university had reached a conundrum: social science research showed that while the number of women college students was monotonically increasing in all areas of science and engineering, the number of female faculty in STEM had stagnated to single digits, in both absolute numbers and percentages. Consequently, in the late 1990s the National Science Foundation announced ADVANCE, a program to help academic institutions understand and address the underrepresentation of women in STEM. Michigan was one of the first three universities that received such a grant in 2002, under the leadership of then-Provost Nancy Cantor (https://advance.umich. edu/). The goal of the grant was to initiate institutional transformation, by using evidence-based interventions.

The programs developed at Michigan under this five-year grant provided a strong foundation on which to build the proposal that UC Davis submitted to NSF ADVANCE program in 2011 during my second year as a chancellor of that institution. The UC Davis proposal aimed to address, for the first time, underrepresentation in the STEM professoriate at the intersections of gender and race. For UC Davis as well as many other U. S. institutions, realizing that gender's intersection with race was critical to understanding the increasing gap between diversity in student demographics and faculty diversity. Throughout the University of California system, and more specifically at UC Davis, Latinx students had been the growing majority of the incoming class (close to $25 \%$ ), while Latinx faculty had consistently remained below six percent across all STEM areas. We therefore chose to focus our ADVANCE program on increasing the number of Latina faculty in STEM fields, in parallel with our institution's efforts to become a Hispanic-Serving Institution (HSI). In less than five years, UC Davis succeeded in recruiting 16 Latina scientists and engineers as faculty members across many science and engineering disciplines.

The UC Davis ADVANCE program, together with the move toward HSI status, made visible the wheels of institutional cultural change. Diversifying the professoriate to reflect the demographics of the student and state population not only fulfilled a responsibility toward our students and the public, but also presented an opportunity to increase the impact of the institution in educating future community leaders. At the same time, the campus was consistently placed among the top 10 public institutions in the United States - an indication that the perceived quality of the institution overall had also increased, becoming a direct challenge to the assumption that diversity comes at the expense of quality. For the first time in 2015, the campus was recognized by Forbes as the No. 1 institution in the nation in the number of women teaching in the life sciences. In 2019, it received the Sea Change Bronze Award (one of three only institutions in the country) from the American Association for the Advancement of Science (https://seachange.aaas.org/). 


\section{The Cultural Basis of Intolerance and the Role of Leadership}

A number of experiments have shown that members of groups often feel pressure to conform, or feel anxiety about countering what they perceive as normative or prevailing points of view. If the prevailing viewpoint is continuously reinforced, eventually these group members accept the point of view as their own and become strong supporters of the culture. These tactics work either in favor or against progressive change in a community, inflicting what Hannah Arendt called "the banality of evil."

Human history is full of powerful demonstrations of negative conformity practiced at a state level. Consider the trial of Socrates, the killing of "witches" in Salem, Jim Crow laws in the American South, the Holocaust in Europe, genocide in Rwanda, and apartheid in South Africa. By contrast, enforcing positive values has resulted in laws around the world prohibiting discrimination, including racism, gender- and sexdiscrimination, homophobia, anti-Semitism, etc. Yet a lack of open debate can lead to the rise of opposing subcultures that feel victimized and go underground, only to emerge at a later time when triggered by social or political events (e.g., the increased visibility/activity of white supremacists in the United States after the election of Donald Trump). Lack of dialogue has been strengthened in recent years by the Internet and social media, which allow people to easily find affinity groups no matter their geographic location. This reminds us of the importance of strong leadership in supporting progressive cultural change and opposing the politics of intolerance. Although such observations pertain primarily to societal-level dynamics, the same can be argued about smaller organizations and institutions.

No academic institution can embrace tolerance and engrave it in their culture unless its leadership remains vigilant as well as vocal. A silent leadership places the institution at risk. By silence, I mean the inability to openly defend progressive institutional values at every opportunity available. When silence is the response, there is always the chance that elements opposing progress will feel empowered and act publicly.

The core elements of an institutional culture are often implicit; they are practiced in daily routines, they give a common direction to the members of the institution, and they are the result both of learning and of internal coordination. To revisit Plotkin (2003), they enable a "collective identity" not reducible to any one group. Furthermore, although collective identities cultivate a view of the world (Plotkin's notion of collective "intentionality"), this view is ever-evolving and open to change. Individuals do not consciously learn an institutional culture, but they do internalize it during a process of socialization and self-reflection. This implies that institutional transformation can take place only in the presence of an institutional culture-a collective identity - that values introspection and debate, and with a leadership that vigorously defends inclusiveness while condemning intolerance. 


\section{Silent Leadership and Conformity}

Very few social, public, or business organizations, and few communities, actively encourage cultural or political nonconformity. In most organizations, nonconformists are dismissed, ostracized, or even forced out. They are considered to be disruptive and threatening. Yet, while nonconformism is a disruptive force, it can also become a powerful tool for progressive change.

A community or organizational culture that avoids challenge and considers questioning and new ideas as threats to its well-being is nonprogressive at best and autocratic at worst. Such cultures exist widely today, embracing various political orientations. Creating a progressive organization requires an enlightened leadership and a strong, open-to-change, and confident collective identity. Weak leadership is mostly defined by what it is not doing.

I offer three personal examples as evidence. When I was announced as the first female Dean of Engineering at Purdue in the fall of 2001, I received an email from Denice Denton, then Dean of Engineering at the University of Washington, in Seattle, who thanked me for increasing the number of female engineering deans in the United States by $20 \%$. With me included, we became a total of just six female engineering deans in the country: Denton at the University of Washington, Christina Johnson at Duke, Ilene Bush-Vishniac at Johns Hopkins, Janie Fouke at Michigan State, and Eleanor Baum at Cooper Union. I was the sixth engineering dean, at Purdue. All of us went through higher levels of administration and probably faced every single form of prejudice and contempt that has been defined in the literature on gender stereotyping and discrimination. Too often, when our leadership was challenged, our institutions remained silent.

The most egregious case is that of Denice Denton, who went on from her dean role to become the first openly gay chancellor in the University of California system. Her appointment at UC Santa Cruz, announced in 2005, was received with suspicion and criticism by a community that nevertheless branded itself as liberal. Among all UC chancellors, Denice was targeted by students, the unions, and the Santa Cruz community for the following: her salary, not even the highest among the UC chancellors; renovations of the physically neglected Chancellor's Residence, which she was expected to occupy; and nepotism involving the recruitment of her partner, under a program that the University of California regularly uses to recruit faculty and their partners on all 10 of its campuses. The local newspaper published negative stories against Denice almost every day, directly encouraging students to push her out of the chancellor's position. Over a period of a year and a half, individuals claiming to be students or representing labor unions threatened her physically and abused her emotionally. During that period, the Office of the UC President refrained from providing any support to her and declined to give a public explanation for actions they approved. In June of 2006, Denice, fell into a deep depression and jumped to her death from her San Francisco apartment (Sonnenfeld, 2006).

A year later, M. R. C. Greenwood, a previous chancellor of UC Santa Cruz and a provost in the University of California system, was also publicly accused of nepotism, 
an allegation that was proven false. Under tremendous public scrutiny and media attacks, she resigned from her position. She, too, was treated with bias and contempt and was publicly deemed unfit for the job. The UC Office of the President observed the attacks with apparent indifference and silence, making itself an accomplice to the hateful actions by the media and the broader public.

The last example involves a personal experience. After I was falsely accused by the President of the University of California of nepotism, among other things, my reputation as a person and a leader was ruined, and I was asked to step down from my chancellor's position. It was the support of my family and friends who helped me survive the crisis and avoid taking action similar to Denice's. They helped me decouple my true self from the straw person that had been created by a local newspaper, a community feeling deep contempt for a female chancellor, and a President with significant political insecurities. In this case, the UC Office of the President did not just remain silent; it played the role of executioner.

A year and a half after my resignation as a chancellor, the UC Davis student newspaper published an article titled "Linda Katehi or Lizard Katehi" (Hanson, 2018), written by a male student who considered his article humorous. He writes about a fictional encounter with me in the university library, and his reference to "moonlighting" is a critique of my service on a corporate board of directors, despite the fact that 39 men in the UC leadership structure had similar appointments. In his effort to be witty, and oblivious to gender discrimination, the student wrote:

...This was [in the library], where she [Katehi] made her move on me. I wasn't uncomfortable with the situation, but I said that it would be moonlighting since I do much of my sex work outside of school and rely entirely on "tips." She said that there was no potential for pregnancy since she was asexual and reproduced through parthenogenesis, and when questioned on STDs, she said that the only diseases she spread were occasionally plague in her human form, when afflicted by fleas, and sometimes anthrax when moonlighting for the United States' chemical weapons deployment team in South America. That last one she only did around Christmas, though—for extra gift money, mainly...

This particular paragraph of the article, written in the style of Generation Z, articulates the stereotypes and prejudice of our society toward all female science and engineering faculty of my generation. These are women who have fought hard against inequality just to do one thing: be given an equal opportunity to attain their dreams.

This student's article could have provided a unique opportunity for university leaders to engage both Generation $\mathrm{Z}$ and the general community in a dialogue that would have reemphasized the cultural values and principles that have characterized UC Davis for the past many years, and would also remind young people that stereotypes harm even when offered as humor. Yet again the university administration chose to remain silent and, in the process, became an accomplice to the sexism the article openly expressed. Silence defaced the very soul of the institution and stripped its culture from the only defense it has against stereotyping and prejudice-its ability to publicly lead an instructive dialogue. 


\section{Conclusion: Battling Gender Stereotyping and Prejudice}

In view of what I have written, I would like to credit the efforts of scholars over the past 60 years to battle gender discrimination and am compelled to mention the changes I have personally observed. In 1972, I entered the electrical engineering program as a freshman, one of two young women among 198 young men, in the National Polytechnic of Athens, Greece. I was explicitly told by the class student president that I unfairly took a position from a young man who could put the engineering degree to good use. Since then, substantial positive change has happened in that specific engineering college, as well as others both in the U.S. and around the world; now women are expected and actively invited to join my profession. At present, we expect to see at least $20 \%$ of women in even the most conservative engineering departments.

In August of 1984, I was hired as an assistant professor of electrical engineering at the University of Michigan, at a substantially lower salary than a younger male colleague with similar experience to mine. When I asked why I was being underpaid, the administration said they expected me to spend less effort as a faculty member because I had a five-month-old son. Today, this explanation would be dismissed and disciplined. In 1987, when, as an assistant professor, I was expecting my daughter, I was told by my lab's administration that no maternity programs existed for women faculty, so I could choose to stay at home during the first six weeks, at no salary. Today, there is no academic institution that I know of throughout the United States that lacks a minimal maternity program for female faculty.

In my almost 50 years in higher education, I have had a wonderful and satisfying career that speaks to the amazing progress in lessening gender discrimination in academic. After all, I was the first immigrant woman to be the Dean of Engineering at Purdue University, the Provost at the University of Illinois, Urbana Champaign, and Chancellor at UC Davis. In 2015, I was the first woman in the history of the National Academy of Engineering to receive the prestigious Ramo Simon Founder's Award which was established in 1964. Yet the same successful career gifted me with numerous negative and harmful experiences that have left many emotional scars, suggesting that much more needs to be done to eradicate gender discrimination in academia. Stories from educators and administrators like me need to be told, to help the wider society realize that we have not arrived yet, and that the dream of our foremothers who fought for equal opportunity and equal treatment has yet to come true.

\section{References}

Amodio, D. M. (2009). On the interpersonal functions of implicit stereotyping and evaluative race bias: Insights from social neuroscience. In R. E. Petty, R. H. Fazio, \& P. Briñol (Eds.), Attitudes: Insights from the new wave of implicit measures. Erlbaum. 
Amodio, D. M. (2011). A memory systems model of implicit social cognition. Current Directions in Psychological Science, 143.

Baldwin, J. (2017). Culture, Prejudice, Racism, and Discrimination. Communication, Oxford Research Encyclopedias. https://doi.org/10.1093/acrefore/9780190228613.013.164.

Baldwin, J. R., Faulkner, S. L., Hecht, M. L., \& Lindsley, S. L. (2006). Redefining culture: Perspectives across the disciplines. Lawrence Erlbaum and Associates.

Benedict, R. (1938). Continuities and discontinuities in cultural conditioning. Psychiatry, pp. 16167.

Boaz, F. (1915). Race and Nationality. Special Bulletin, 63-77.

Correll, J. P. (2007). The influence of stereotypes on decisions to shoot. European Journal of Social Psychology, 1102.

Darwin, C. (1892). An autobiography.

Ebert, R. J. (2009). Business essentials. Prentice Hall.

European, U. (2019). Gender equality, definition. https://eige.europa.eu/gender-mainstreaming/too lkits/gender-institutional-transformation/what-institutional-transformation

Flannigan, N., Miles, L. K., Quadflieg, S., \& Macrae, C. N. (2013). Seeing the unexpected: Counterstereotypes are implicitly bad. Guilford Press Periodicals; Social Cognition, 712-720.

Forbes, C. E. (2010). Retraining attitudes and stereotypes to affect motivation and cognitive capacity under stereotype threat. Journal of Personality and Social Psychology, 740.

Gawronski, B. A. (2006). Associative and propositional processes in evaluation: An integrative review of implicit and explicit attitude change. Psychological Bulletin, 692.

Gawronski, B., \& Bodenhausen, G. (2011). The associative-propositional evaluation model: Theory, evidence, and open questions. Advances in Experimental Social Psychology, 59.

Glaser, J. C. (1999). The relation between stereotyping and prejudice: Measures of newly formed automatic associations. Dissertation Abstracts International: Section B: The Sciences and Engineering, 2409-18.

Greenwald, A. G. (2002). A unified theory of implicit attitudes, stereotypes, self-esteem, and selfconcept. Psychological Review, 3.

Hanson, D. (2018, March). California Aggie. Retrieved from https://theaggie.org/2018/03/20/ humor-linda-katehi-or-lizard-katehi/

Jacobs, R. C., \& Campbell, D. T. (1961). The perpetuation of an arbitrary tradition through several generations of a laboratory microculture. The Journal of Abnormal and Social Psychology, 64958.

Judd, C. M. (2004). Automatic stereotypes vs. automatic prejudice: Sorting out the possibilities in the weapon paradigm. Journal of Experimental Social Psychology, 75.

Madva, A. (2016). Virtue, social knowledge, and implicit bias. Implicit bias and philosophy, Vol. 1: Metaphysics and epistemology. Oxford University Press.

Mandelbaum, D. G. (1985). Writings of Edward Sapir. University fo California Press.

Marx, K. (1911). A contribution to the critique of political economy. Charles H. Kerr and Company.

Mazda, A., \& Brownstein, M. (2016). Stereotypes, prejudice, and the taxonomy of the implicit social. Mind. https://doi.org/10.1111/nous.12182

Mead, M. (1970). Culture and commitment. Natural History Press.

Moon, G., \& Kern, R. (2002). From medical to health geography: Novelty, place and theory after a decade of change. Progress in Human Geography, 26(5), 605-625.

Plotkin, H. (1994). Darwin machines and the nature of knowledge. Harvard University Press.

Plotkin, H. (2003). We-intentionality: An essential element in understanding human culture? Perspectives in Biology and Medicine, 46(2), 283-296.

Plotkin, H. (2007). The power of culture. Handbook of evolutionary psychology (pp. 12-19).

Plotkin, H. (2011). Human nature, cultural diversity and evolutionary theory. Transactions of the Royal Society.

Rudman, L. A., \& Ashmore, R. D. (2007). Discrimination and implicit association test. SAGE Journals: Discrimination and Implicit Association. https://doi.org/10.1177/1368430207078696 
Rudman, L. A., \& Kilianski, S. E. (2000). Implicit and explict attitudes towards female authority. Personality and Social Psychology Bulletin. https://doi.org/10.1177/0146167200263001

Sonnenfeld, J. (2006). A complex tragedy: Denice Denton and UC Santa Cruz. https://www.ind ybay.org/newsitems/2006/07/02/18284785.php

Thorley, J. (1996). Athenian democracy. Routledge.

Valian, V. (1998). Why so slow? The advancement of women. MIT Press.

Valian, V. (2009, January). Beyond gender schemas: Improving the advancement of women in academia. Hypatia: Journal on Feminist Philosophy.

Open Access This chapter is licensed under the terms of the Creative Commons Attribution 4.0 International License (http://creativecommons.org/licenses/by/4.0/), which permits use, sharing, adaptation, distribution and reproduction in any medium or format, as long as you give appropriate credit to the original author(s) and the source, provide a link to the Creative Commons license and indicate if changes were made.

The images or other third party material in this chapter are included in the chapter's Creative Commons license, unless indicated otherwise in a credit line to the material. If material is not included in the chapter's Creative Commons license and your intended use is not permitted by statutory regulation or exceeds the permitted use, you will need to obtain permission directly from the copyright holder.

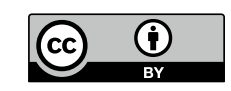

